Supporting Information for

\title{
Field-Induced Relaxation of Magnetization in A Three-Dimensional LnMOF with the Second Bridging Ligand Squarate
}

\author{
Cai-Ming Liu, ${ }^{\dagger *}$ Deqing Zhang, ${ }^{\dagger}$ Xiang Hao, ${ }^{\dagger}$ and Dao-Ben $\mathrm{Zhu}^{\dagger}$ \\ ${ }^{\dagger}$ Beijing National Laboratory for Molecular Sciences, Center for Molecular Science, \\ Key Laboratory of Organic Solids, Institute of Chemistry, Chinese Academy of \\ Sciences, Zhongguancun North Street No. 2, Beijing 100190, P. R. China. E-mail: \\ cmliu@iccas.ac.cn
}


Table S1. Continuous Shape Measures calculation for the Dy1 atom in $\mathbf{1 .}$

S H A P E $\quad$ v2.1 Continuous Shape Measures calculation
(c) 2013 Electronic Structure Group, Universitat de Barcelona

Contact: 11une11@ub. edu

Dy structures

$\begin{array}{lll}\text { OP-8 } & 1 \mathrm{D} 8 \mathrm{~h} & \text { Octagon } \\ \text { HPY-8 } & 2 \mathrm{C} 7 \mathrm{v} & \text { Heptagonal pyramid } \\ \text { HBPY-8 } & 3 \mathrm{D} 6 \mathrm{~h} & \text { Hexagonal bipyramid } \\ \text { CU-8 } & 4 \text { Oh } & \text { Cube } \\ \text { SAPR-8 } & 5 \text { D4d } & \text { Square antiprism } \\ \text { TDD-8 } & 6 \text { D2d } & \text { Triangular dodecahedron } \\ \text { JGBF-8 } & 7 \text { D2d } & \text { Johnson gyrobifastigium J26 } \\ \text { JETBPY-8 } & 8 \text { D3h } & \text { Johnson elongated triangular bipyramid J14 } \\ \text { JBTPR-8 } & 9 \text { C2v } & \text { Biaugmented trigonal prism J50 } \\ \text { BTPR-8 } & 10 \mathrm{C} 2 \mathrm{v} & \text { Biaugmented trigonal prism } \\ \text { JSD-8 } & 11 \text { D2d } & \text { Snub diphenoid J84 } \\ \text { TT-8 } & 12 \mathrm{Td} & \text { Triakis tetrahedron } \\ \text { ETBPY-8 } & 13 \mathrm{D} 3 \mathrm{~h} & \text { Elongated trigonal bipyramid }\end{array}$

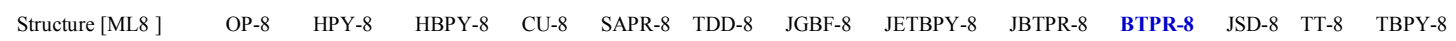

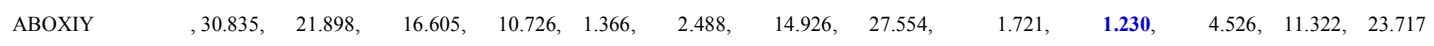




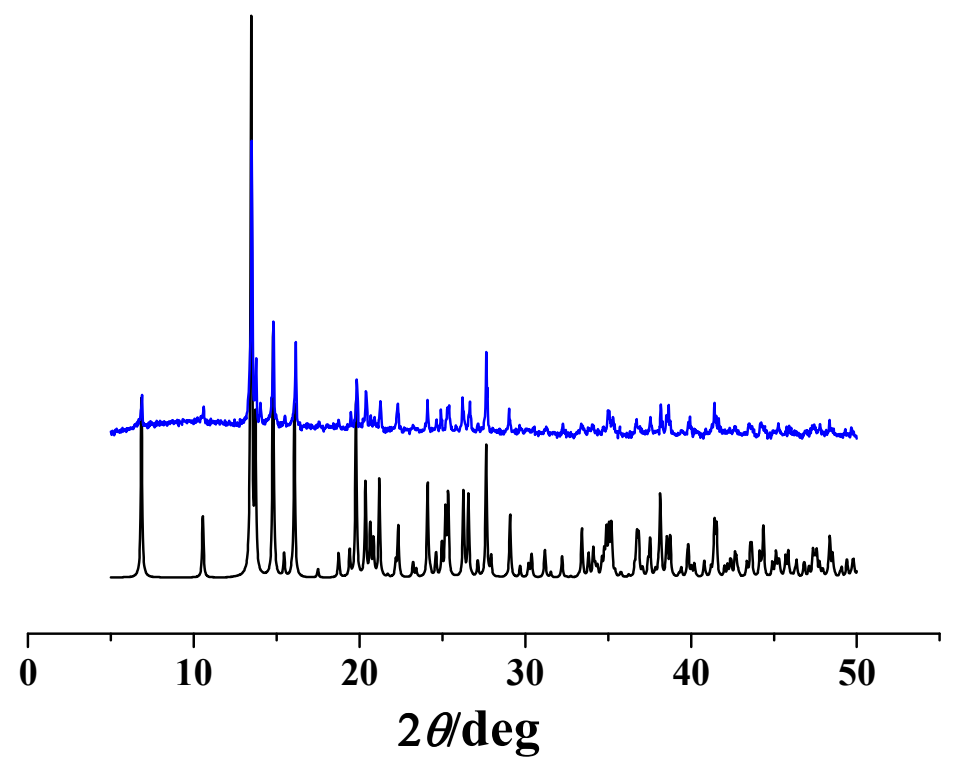

Figure S1. The powder X-ray diffraction pattern (blue) and the simulative pattern (black) for $\mathbf{1}$.

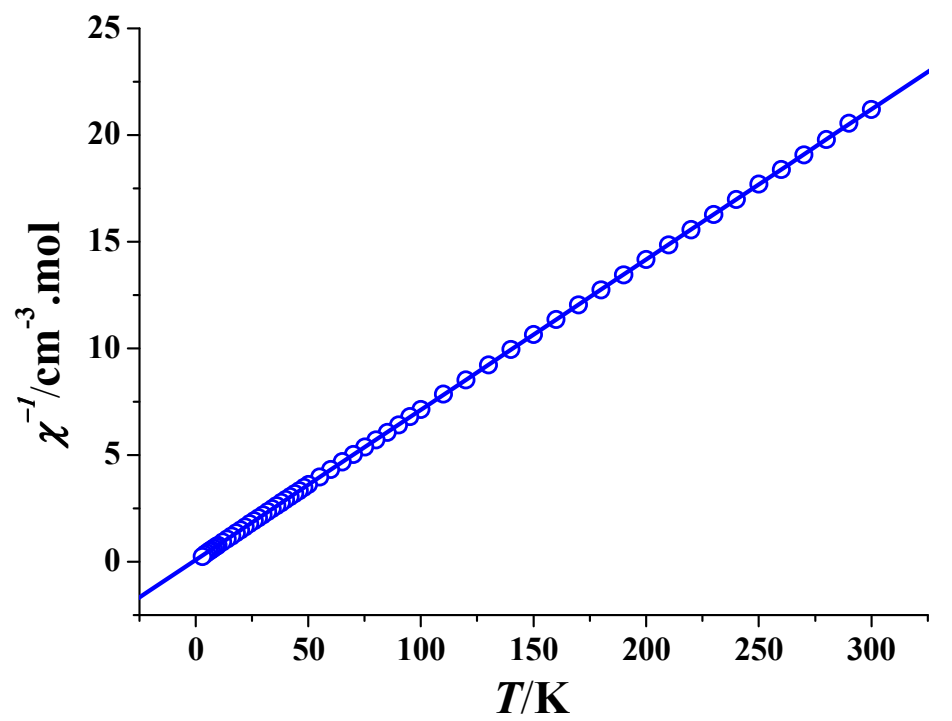

Figure S2. $\chi^{-1}$ versus $T$ plot of $\mathbf{1}$. 


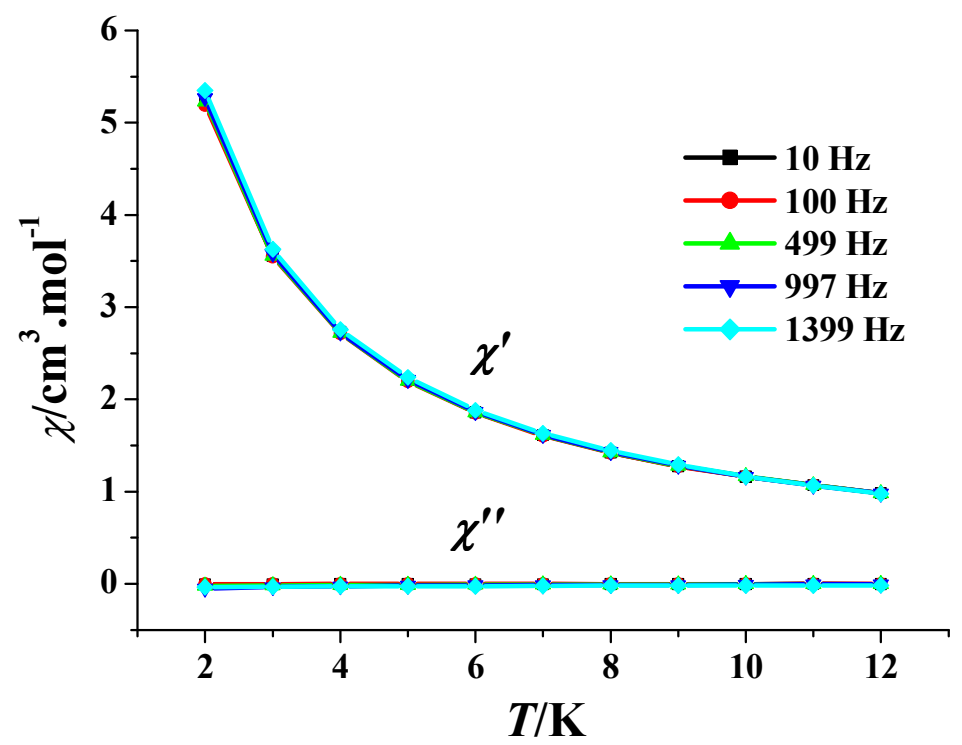

Figure S3. AC susceptibilities measured in a 2.5 Oe ac magnetic field with a zero dc field for $\mathbf{1}$.
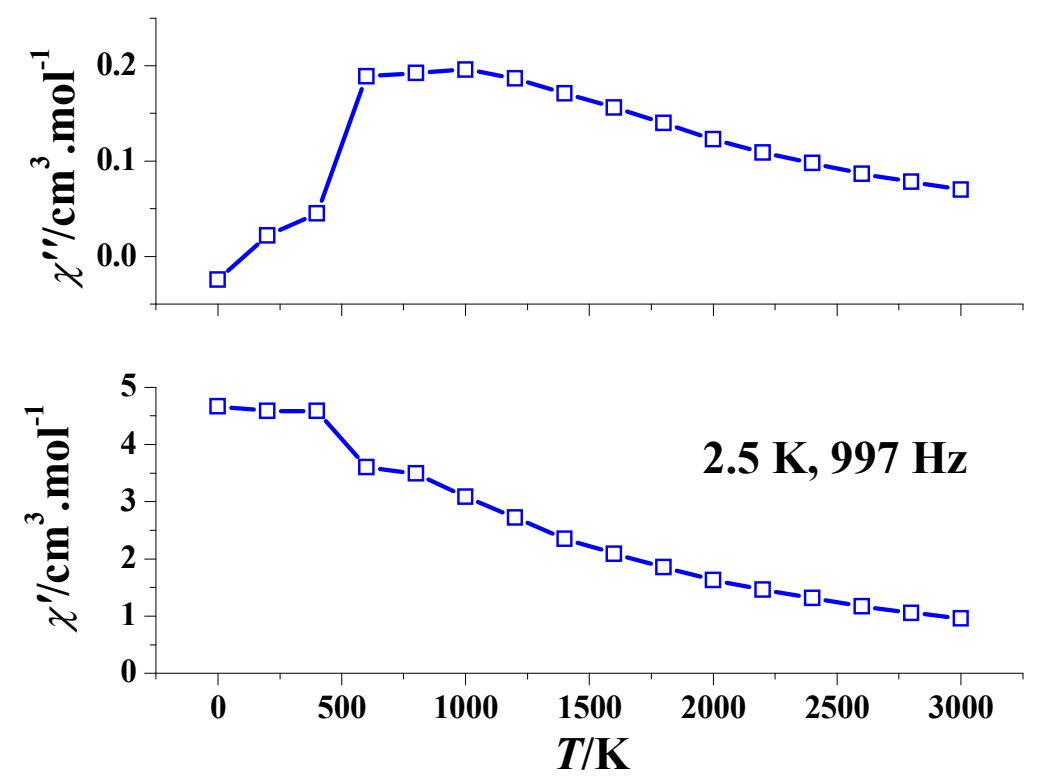

Figure S4. AC susceptibilities measured in a 2.5 Oe ac magnetic field with variable dc fields at $997 \mathrm{~Hz}$ and $2.5 \mathrm{~K}$ for $\mathbf{1}$. 


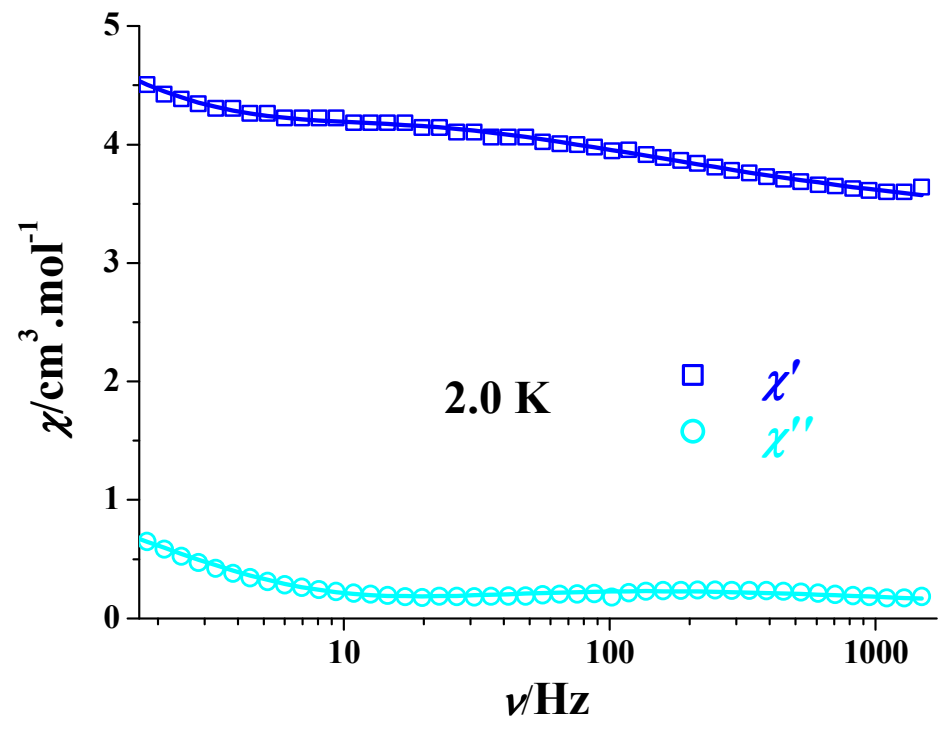

Figure S5. Frequency dependence of the in-phase $\left(\chi^{\prime}\right.$, top) and out-of-phase $\left(\chi^{\prime \prime}\right.$, bottom) ac susceptibility of 1 at $2.0 \mathrm{~K}$. the solid lines represent the best fitting with the sum of two modified Debye functions.

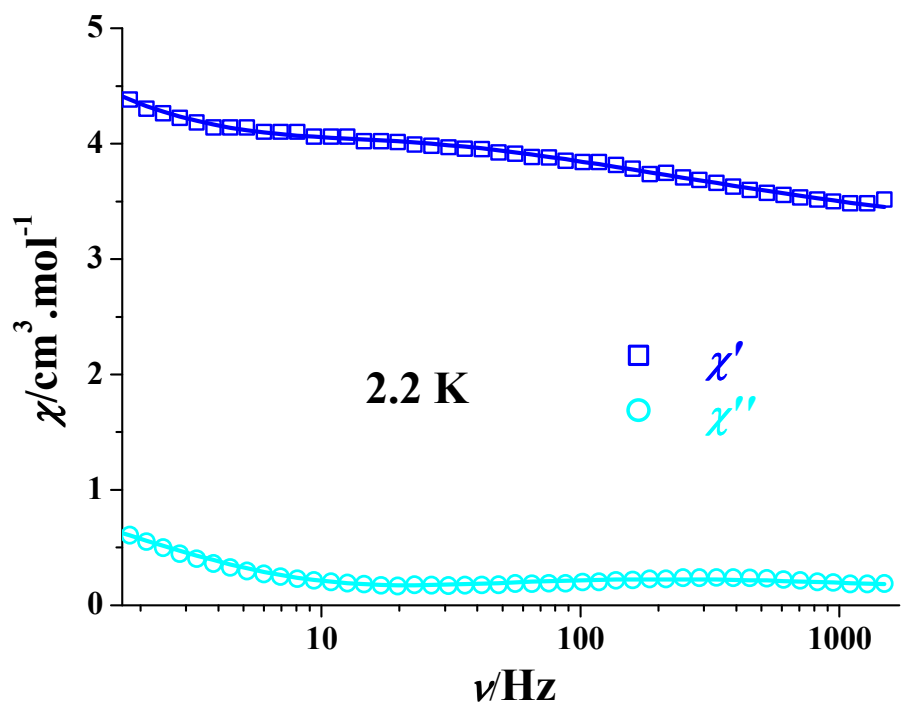

Figure S6. Frequency dependence of the in-phase ( $\chi^{\prime}$, top) and out-of-phase $\left(\chi^{\prime \prime}\right.$, bottom) ac susceptibility of $\mathbf{1}$ at $2.2 \mathrm{~K}$. the solid lines represent the best fitting with the sum of two modified Debye functions. 


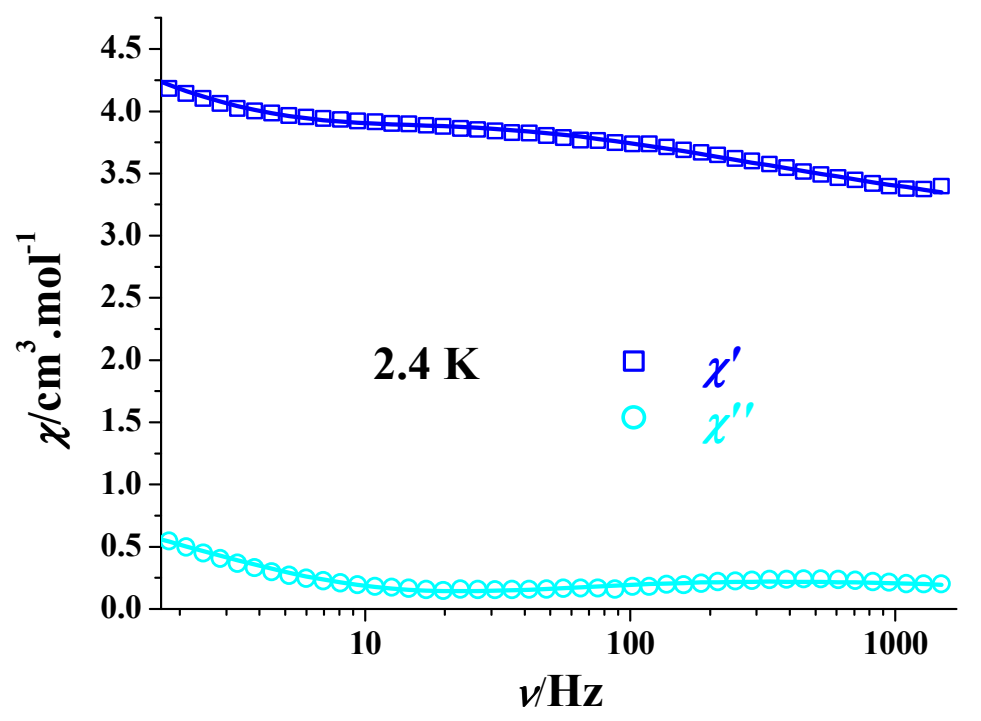

Figure S7. Frequency dependence of the in-phase ( $\chi^{\prime}$, top) and out-of-phase $\left(\chi^{\prime \prime}\right.$, bottom) ac susceptibility of 1 at $2.4 \mathrm{~K}$. the solid lines represent the best fitting with the sum of two modified Debye functions.

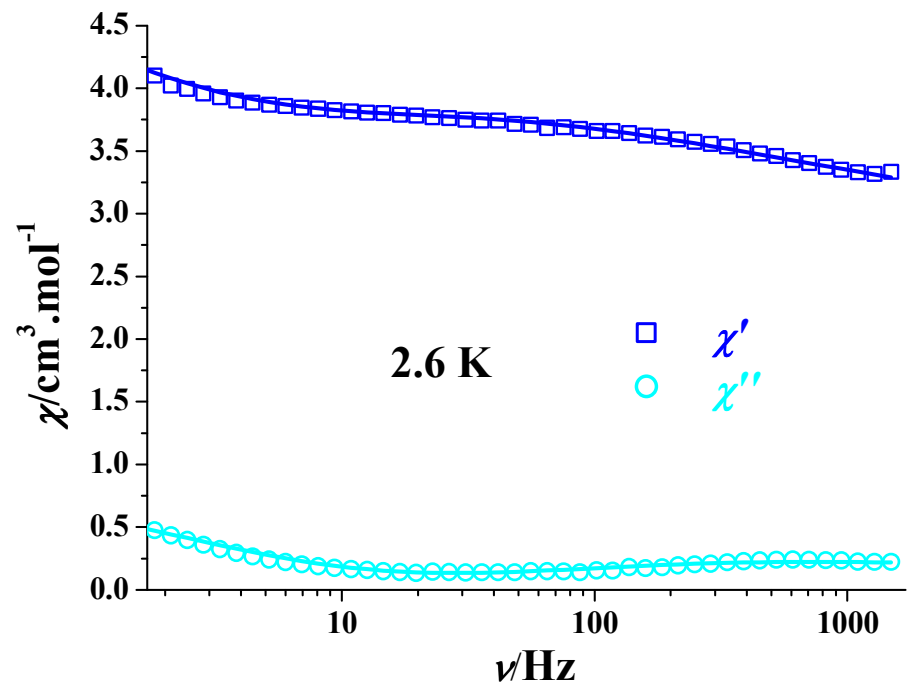

Figure S8. Frequency dependence of the in-phase ( $\chi^{\prime}$, top) and out-of-phase ( $\chi^{\prime \prime}$, bottom) ac susceptibility of 1 at $2.6 \mathrm{~K}$. the solid lines represent the best fitting with the sum of two modified Debye functions. 


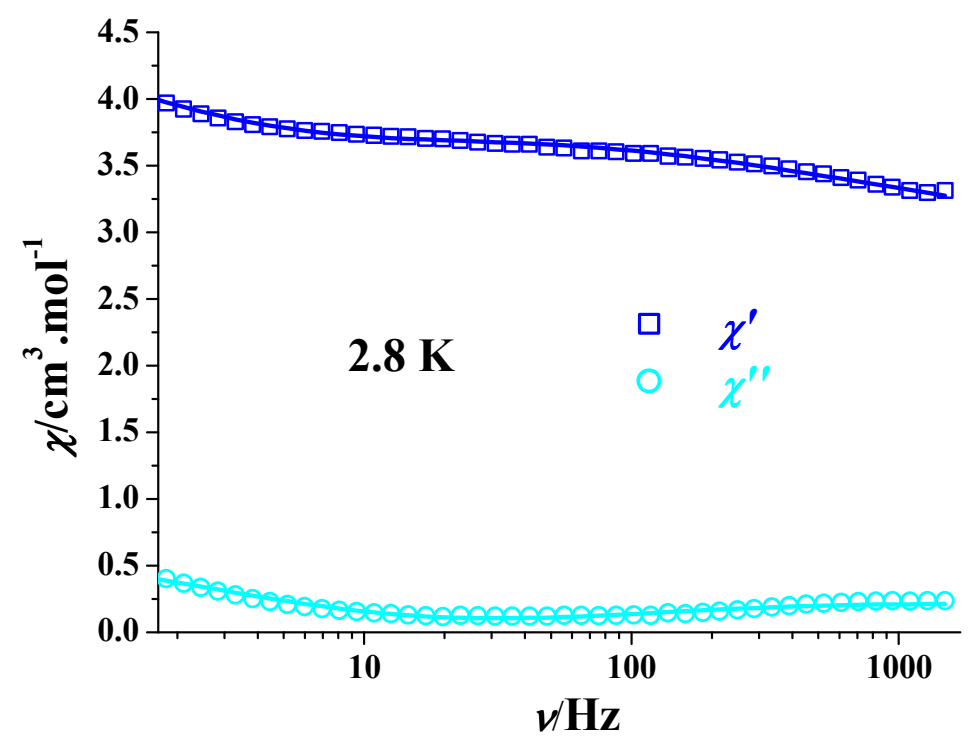

Figure S9. Frequency dependence of the in-phase $\left(\chi^{\prime}\right.$, top) and out-of-phase $\left(\chi^{\prime \prime}\right.$, bottom) ac susceptibility of 1 at $2.8 \mathrm{~K}$. the solid lines represent the best fitting with the sum of two modified Debye functions.

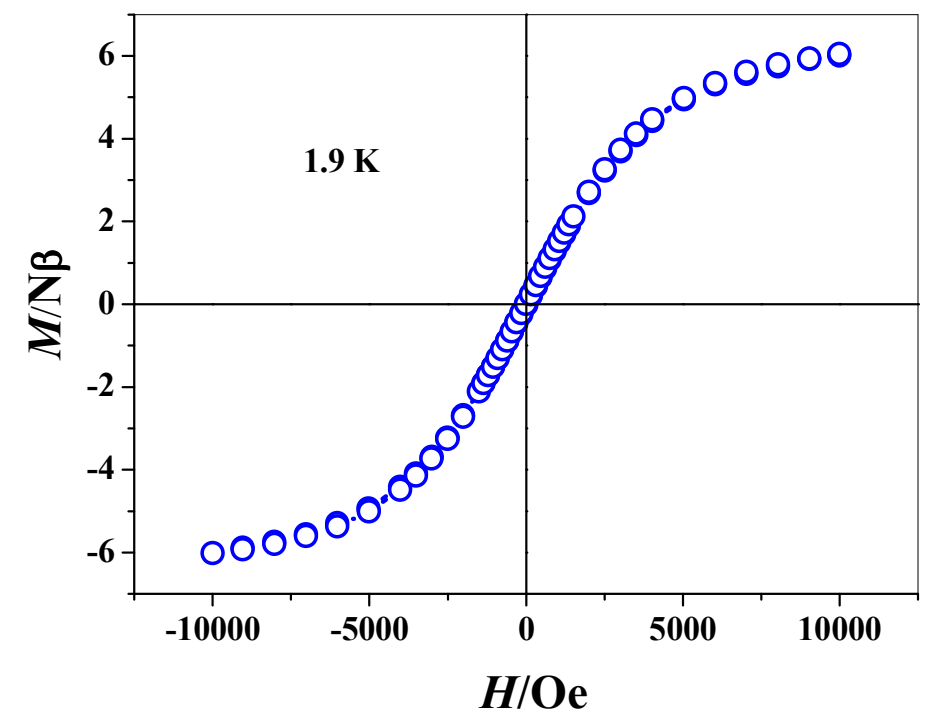

Figure S10. Plot of $M$ versus $H$ at $1.9 \mathrm{~K}$ from -10000 to 10000 Oe for $\mathbf{1}$. 
Table S2. Linear combination of two modified Debye model fitting parameters at 2.0-2.8 K of 1 under a de field of 1000 Oe.

\begin{tabular}{|l|l|l|l|l|l|l|l|}
\hline$T(\mathrm{~K})$ & $\chi_{2}\left(\mathrm{~cm}^{3} \cdot \mathrm{mol}^{-1}\right)$ & $\chi_{1}\left(\mathrm{~cm}^{3} \cdot \mathrm{mol}^{-1}\right)$ & $\chi_{0}\left(\mathrm{~cm}^{3} \cdot \mathrm{mol}^{-1}\right)$ & $\tau_{1}(\mathrm{~s})$ & $\alpha_{1}$ & $\tau_{2}(\mathrm{~s})$ & $\alpha_{2}$ \\
\hline 2.0 & 9.31826 & 0.0139 & 3.25908 & 0.02705 & 0.34982 & 0.25206 & 0.60999 \\
\hline 2.2 & 9.15734 & 3.05782 & 0.00001 & 0.02301 & 0.37545 & 0.26985 & 0.64239 \\
\hline 2.4 & 8.84097 & 0.31007 & 2.85897 & 0.01779 & 0.37479 & 0.31859 & 0.67974 \\
\hline 2.6 & 8.78294 & 0.00003 & 2.57591 & 0.01413 & 0.43057 & 0.33789 & 0.72672 \\
\hline 2.8 & 8.3773 & $8.9983 \mathrm{E}-6$ & 2.41533 & 0.01157 & 0.46041 & 0.35927 & 0.75909 \\
\hline
\end{tabular}

Table S3. Selected crystallographic data and structural refinement parameters for complex 1.

\begin{tabular}{|c|c|}
\hline CCDC & 1478335 \\
\hline Formula & $\mathrm{C}_{10} \mathrm{H}_{6} \mathrm{DyNO}_{8}$ \\
\hline Formula weight & 430.66 \\
\hline Crystal system & monoclinic \\
\hline Space group & $P 2_{1} / c$ \\
\hline$a / \AA$ & $12.9210(16)$ \\
\hline$b / \AA$ & $11.018(2)$ \\
\hline$c / \AA ̊$ & $8.199(3)$ \\
\hline$\beta /^{\circ}$ & $93.83(3)$ \\
\hline$V / \AA^{3}$ & $1164.6(5)$ \\
\hline$Z$ & 4 \\
\hline$T / \mathrm{K}$ & $173(2)$ \\
\hline$\lambda(\mathrm{Mo}-\mathrm{K} \alpha) / \AA$ & 0.71073 \\
\hline$\rho_{\text {calc }} / \mathrm{g} \cdot \mathrm{cm}^{-3}$ & 2.456 \\
\hline$\mu(\mathrm{Mo}-\mathrm{K} \alpha) / \mathrm{mm}^{-1}$ & 6.457 \\
\hline$\theta$ range & $3.16^{\circ} \leq \theta \leq 27.42^{\circ}$ \\
\hline Limiting indices & $\begin{array}{l}-15 \leq h \leq 16, \\
-13 \leq k \leq 14,-10 \leq l \leq 10\end{array}$ \\
\hline Reflections collected & 8493 \\
\hline Unique reflections & 2631 \\
\hline$R_{l}^{a}[I>2 \sigma(I)]$ & 0.0268 \\
\hline${ }_{W} R_{2}^{b}[I>2 \sigma(I)]$ & 0.0662 \\
\hline$R_{1}^{a}$ [all data] & 0.0271 \\
\hline${ }_{W} R_{2}^{b}$ [all data] & 0.0665 \\
\hline$S$ & 1.175 \\
\hline
\end{tabular}

